\title{
Reliability of three foot models to examine paediatric gait
}

\author{
Ryan Mahaffey*, Stewart Morrison, Wendy Drechsler, Mary Cramp \\ From 3rd Congress of the International Foot and Ankle Biomechanics Community \\ Sydney, Australia. 11-13 April 2012
}

\begin{abstract}
Background
A variety of multi-segmental foot models have been produced to examine patterns of foot segmental movement during gait cycle to identify biomechanical differences between normal and pathological foot function[1-3]. The reliability of foot models to accurately describe motion of the foot joints is dependent on the ability of the examiner to repeatedly apply markers to specific landmarks and the relevance of models' segmental descriptions to underlying anatomy. The aim of this study was to test the reliability of segmental angles measured by three published foot models during paediatric gait.
\end{abstract}

\section{Materials and methods}

Sixteen children, aged 6 to 12 years old, were recruited to the study. Marker sets for three foot models 3DFoot [1], Oxford Foot Model (OFM)[2], and Kinfoot[3] were applied to their right feet simultaneously which to the authors knowledge, is the first direct comparison of the three models during gait. Each foot model was assessed for repeatability of maximal joint angle and range of motion during the gait cycle between two testing occasions. Absolute angular differences and standard error of measurement (SEM) are reported.

\section{Results}

Repeatability of all maximal segmental angles and range of motions were higher in 3DFoot compared to OFM and Kinfoot (Table 1).

\section{Conclusion}

Decreased measurement error observed in 3DFoot and Kinfoot models may be attributable to normalisation of kinematics data to subject standing position. In the
Table 1 Inter-session repeatability of foot model's 3D maximal segmental angles over the gait cycle.

\begin{tabular}{llcccc}
\hline Model & Segments & \multicolumn{2}{c}{$\begin{array}{c}\text { Maximal joint } \\
\text { angle } \\
\end{array}$} & & \multicolumn{2}{c}{$\begin{array}{c}\text { Range of joint } \\
\text { angle }\end{array}$} \\
& & Difference & $\begin{array}{c}\text { SEM } \\
{ }^{\circ}\end{array}$ & $\begin{array}{c}{ }^{\circ} \\
\text { Difference }\end{array}$ & $\begin{array}{c}\text { SEM } \\
{ }^{\circ}\end{array}$ \\
\hline OFM & Hindfoot to Shank & $2.1 \pm 15.1$ & 10.9 & $1.2 \pm 8.0$ & 5.7 \\
3DFoot & Hindfoot to Shank & $1.0 \pm 5.2$ & 3.6 & $1.0 \pm 4.6$ & 3.3 \\
Kinfoot & Hindfoot to Shank & $1.0 \pm 5.1$ & 3.6 & $1.4 \pm 6.3$ & 4.3 \\
3DFoot & Midfoot to Hindfoot & $0.8 \pm 3.5$ & 2.2 & $0.3 \pm 2.7$ & 1.9 \\
Kinfoot & Midfoot to Hindfoot & $3.0 \pm 11.1$ & 6.7 & $3.7 \pm 11.3$ & 6.6 \\
OFM & Metatarsals to & $0.8 \pm 8.5$ & 5.3 & $1.3 \pm 5.7$ & 5.4 \\
& Hindfoot & & & & \\
3DFoot & Metatarsals to Midfoot & $0.7 \pm 4.0$ & 2.9 & $0.6 \pm 3.6$ & 2.5 \\
Kinfoot & Metatarsals to Midfoot & $2.8 \pm 7.8$ & 4.8 & $2.6 \pm 6.6$ & 3.7 \\
OFM & Hallux to Metatarsals & $2.3 \pm 15.6$ & 11.2 & $0.4 \pm 13.7$ & 9.1 \\
3DFoot & Hallux to Metatarsals & $1.5 \pm 10.0$ & 6.2 & $0.4 \pm 12.6$ & 8.8 \\
Kinfoot & Hallux to Metatarsals & $4.4 \pm 21.8$ & 15.1 & $2.1 \pm 11.8$ & 7.2 \\
\hline
\end{tabular}

OFM, non-normalisation of gait data resulted in variable segmental offsets, particularly in the frontal plane. Greater measurement error was observed for several foot segments in the Kinfoot model. This may be due to discrepancies in model segment definitions in relation to the underlying joint anatomy, especially around the midfoot to hindfoot segments. 3Dfoot model consistently showed the least measurement error in the segment motions examined and thus is appropriate for use to examine foot biomechanics in gait.

Published: 10 April 2012

\section{References}

1. Leardini A, Benedetti M, Berti L, Bettinelli D, Nativo R, Giannini S: Rear-foot, mid-foot and fore-foot motion during the stance phase of gait. Gait Posture 2007, 25:453-462.

*Correspondence: r.mahaffey@uel.ac.uk

School of Health, Sport \& Bioscience, University of East London, UK 
2. Carson M, Harrington M, Thompson N, O'Connor J, Theologis T: Kinematic analysis of a multi-segment foot model for research and clinical applications: a repeatability analysis. J Biomech 2001, 34:1299-2307.

3. MacWilliams B, Cowley M, Nicholson D: Foot kinematics and kinetics during adolescent gait. Gait Posture 2003, 17:214-224.

doi:10.1186/1757-1146-5-S1-018

Cite this article as: Mahaffey et al.: Reliability of three foot models to examine paediatric gait. Journal of Foot and Ankle Research 2012 5(Suppl 1):018.

Submit your next manuscript to BioMed Central and take full advantage of:

- Convenient online submission

- Thorough peer review

- No space constraints or color figure charges

- Immediate publication on acceptance

- Inclusion in PubMed, CAS, Scopus and Google Scholar

- Research which is freely available for redistribution

Submit your manuscript at www.biomedcentral.com/submit 